\title{
Infertility and mental health
}

\section{Myles Doyle \& Angela Carballedo}

\begin{abstract}
SUMMARY
The World Health Organization (WHO) has indicated that $8-12 \%$ of couples worldwide experience infertility, and in recent years the number seeking treatment has dramatically increased. The diagnosis and therapy put a heavy psychological and physical burden on most patients, female and male. The incidence of depression in couples presenting for infertility treatment is significantly higher than in comparable fertile couples. Anxiety is significantly higher in infertile couples than in the general population. Professionals have become aware of the importance of providing educational interventions to address patients' fears and concerns, and to better prepare patients for the demands of treatment. Health professionals should follow a patient-centred approach to provide for the specific needs of the couple. Women in general have a positive attitude to seeking psychological help in the form of cognitive-behavioural therapy, couples counselling and infertility counselling.
\end{abstract}

\section{LEARNING OBJECTIVES}

- Learn about the incidence rates of infertility and its impact on the mental health of the couple.

- Know about infertility treatment and its psychological impact.

- Learn about the different management strategies that can be helpful in the treatment of mental illness associated with infertility.

\section{DECLARATION OF INTEREST}

None.

Infertility is perceived as a problem across virtually all cultures and societies and it affects an estimated $10-15 \%$ of couples of reproductive age (Boivin 2007). The World Health Organization (WHO) has indicated that $8-12 \%$ of couples worldwide experience infertility (Hsu 2002; World Health Organization 2014). Infertility primarily refers to the biological inability of a person to contribute to conception. It may also refer to the state of a woman who is unable to carry a pregnancy to full term (Lash 2008) or to the inability of a couple to achieve pregnancy after at least 1 year of trying to do so without using any means of birth control (Cooper 2010).

In recent years, the number of couples seeking treatment for infertility has dramatically increased for several reasons. First, fertility treatments such as in vitro fertilisation (IVF) and intracytoplasmic sperm injection (ICIS) have become more successful, with long-term cumulative pregnancy rates nearing 70\% (Pinborg 2009). Second, couples are increasingly aware of available services. Third, the proportion of women who are intentionally delaying pregnancy beyond the age of 35 years has increased greatly in the past few decades. Women nowadays tend to start a family at a later age in favour of their educational and professional development. The consequences of advancing maternal and paternal age are relevant not only for the related risks to natural and assisted conception, but also for the outcome of pregnancy (Balasch 2012). Postponement of parenthood seems to be linked to a higher rate of involuntary childlessness and smaller than desired families, because of increased infertility and fetal death as female and male age progresses (Schmidt 2012). It is important to consider the combined effect of higher female and male age on infertility and reproductive outcome in order to advise couples on the best time to start a family. Interestingly, in a recent European survey, many women were unaware of the relationship between age and fecundity, failed to understand when decline begins, or had the impression that their own health and youthful appearance were protective (Domar 2012).

Increased participation in fertility treatment has raised awareness and inspired research about the psychological impact of infertility and infertility treatment. Consideration has been given to the association between psychiatric illness and infertility. Researchers have also looked into the psychological impact of infertility itself and of the prolonged exposure to intrusive infertility treatments on mood and well-being. It is beyond dispute that a diagnosis of infertility and therapy for infertility put a heavy psychological and physical burden on most patients (Greil 2010). Many authors believe that infertility and its treatment cause a life crisis for most couples (Menning 1980; Dunkel-Schetter 1991; Lalos 1999). Although research has shown that the majority of infertile patients show no long-term deficits in life satisfaction, the reduced satisfaction at the time of diagnosis and subsequent treatment does seem to cause difficulties for the couple (Henning 2002; Verhaak 2007).
Myles Doyle is a consultant psychiatrist in North Tipperary and Research Fellow at the Institute of Neuroscience, Trinity College Dublin Ireland. Angela Carballedo is a consultant psychiatrist at Cluain Mhuire, St John of God Hospital, Dublin, and a senior clinical lecturer at the Institute of Neuroscience, Trinity College Dublin, Ireland. Correspondence Dr Angela Carballedo, Institute of Neuroscience, College Green, Trinity College Dublin, Dublin D2, Ireland. Email: carbala@tcd.ie 
The aims of this article are to review the available literature on infertility and its association with mental health difficulties, the impact of treatments for infertility on mental health, and the recommended management strategies.

\section{Psychological aspects of infertility: cause or effect?}

Several variables have been identified as affecting or being associated with infertility. It has been highlighted over the years that one of the most difficult emotional consequences of infertility is the loss of control over one's life, as infertility marginalises other important aspects of life (Cousineau 2007). This might in part be explained by the fact that, during childhood and adolescence, social messages about the importance of parenthood are constantly disseminated, especially in reference to women, showing 'being a mother' as a central role to identity. Therefore, infertile women often experience a sense of loss of identity and feelings of defectiveness and incompetence (Deka 2010).

\section{Anxiety and depression}

Stress, depression and anxiety are common consequences of infertility. A number of studies have found that the incidence of depression in infertile couples presenting for infertility treatment is significantly higher than in fertile controls, with prevalence estimates of major depression in the range of 15-54\% (Downey 1989; Fassino 2002; Chen 2004). It is important to evaluate women at the beginning of their infertility diagnosis and treatment, as most studies have shown that the presence of depressive symptoms is associated with longer duration of treatment (Thiering 1993; Kee 2000; Smeenk 2001; Lok 2002).

Anxiety has also been shown to be significantly higher in infertile couples than in the general population: $8-28 \%$ of infertile couples report clinically significant anxiety, and generalised anxiety disorder is the most common anxiety disorder diagnosed (Anderson 2003; Chen 2004).

The causal role of psychological disturbances in the development of infertility is still a matter of debate. A study by Lapane and colleagues (1995) involving 58 women of child-bearing age reported a twofold increase in risk of infertility among those with a history of depressive symptoms. However, it did not control for other factors that might influence fertility, such as cigarette smoking, alcohol use, decreased libido and body mass index.

Proposed mechanisms through which depression could directly affect infertility involve the physiology of the depressed state, such as elevated
BOX 1 Causal physiological pathways associated with depression and infertility

- Hyperprolactinaemia

- Disruption of the hypothalamic-pituitary-adrenal (HPA) axis

- Hypo- or hyperthyroidism

- Abnormalities in the luteinising hormone regulation

prolactin levels, disruption of the hypothalamicpituitary-adrenal (HPA) axis and thyroid dysfunction (Box 1). A study of 10 depressed and 13 non-depressed women suggested that depression is associated with abnormal regulation of luteinising hormone, a hormone that regulates ovulation (Meller 1997). Changes in immune function associated with stress and depression may also adversely affect reproductive function (Haimovici 1992).

It is clear that further studies are needed to distinguish the direct effects of depression or anxiety from associated symptoms and/or behaviours (e.g. low libido, smoking, alcohol use) that may interfere with reproductive success. An interesting paper by Moura-Ramos and colleagues (2012) has recently highlighted that stress-related indirect factors such as socioeconomic status and place of residence may have an impact on emotional distress (defined as tension, nervousness or worry not fulfilling criteria for a diagnosis of depression or anxiety disorder). The authors noted that contextual factors indirectly affect emotional distress by shaping the way the infertility is experienced by men and women. They also found that the indirect effects, although found in both men and women, are less predictive of men's emotional distress than of women's.

Since emotional distress is also associated with physiological changes, this raises the possibility that a history of high levels of cumulative stress associated with recurrent depression or anxiety may also be causative factors in infertility (Deka 2010). Supporting this view is the Harvard Study of Moods and Cycles by Harlow and colleagues (2003). This showed that a lifetime history of depression may be associated with early decline of ovarian function.

Fertility in women with a diagnosis of affective illness or schizophrenia has also been suggested to be reduced (Jonsson 1991). A study involving women and men with bipolar illness found that fertility was reduced in both genders even before onset of the illness. After illness onset, the overall reduction remained the same in women, but increased further in men (Baron 1982). Calzeroni 
et al (1990) studied fertility rates in women with a diagnosis of major depression with psychotic features and women with suicidal behaviours. They concluded that those who had attempted suicide had significantly fewer children than those who had not. There were no significant differences in rates of childlessness between the women with and without delusions, but women without psychotic features had higher levels of infertility (Calzeroni 1990).

\section{Psychotropic medication}

Several psychotropic medications may affect infertility, but the literature in this area is very limited. For example, the effect of antidepressants on fertility has not been fully investigated and the literature regarding their use in pregnancy and rates of spontaneous abortions is conflicting (Gentile 2008; Kjaersgaard 2013). However, a meta-analysis found that exposure to antidepressants was associated with a significant increase in spontaneous abortion rates (Hemels 2005). Another study reviewed the outcome of IVF treatment in women taking antidepressants. The authors found that $40 \%$ of women taking antidepressants had ongoing pregnancies compared with 51\% not taking antidepressants (Klock 2004).

There are no studies of the influence of mood stabilisers on fertility rates. It has been suggested that valproic acid may reduce fertility through its effect on hyperandrogenism, hyperinsulinaemia and dyslipidaemia and menstrual abnormalities (Morrel 2003; Rasgon 2004).

Atypical antipsychotics (in particular risperidone) have been associated with increased prolactin levels even at low doses, and thereby independently influence fertility (Haddad 2004). Only a few studies have looked at the effects of antipsychotic medication on pregnancy outcome and spontaneous abortions and they found no association between the two variables (McKenna 2005; Coppola 2007; Habermann 2013).

\section{Treatment for infertility and its emotional impact}

Many women have reported finding treatment for infertility stressful and a cause of relationship difficulties with their partners (Carter 2011). By contrast, however, a European survey concluded that, despite reporting increased stress in certain areas of their relationships with partners, family and friends, women in treatment felt that they received more support from friends and family and felt closer to their partners than women who were not in treatment (Domar 2012). This survey also indicated that women undergoing treatment were more likely to feel hopeful and less concerned about many aspects of the therapy. However, fear of failure was the most important barrier to treatment. Anxiety regarding the daily injection schedule was the second most worrying aspect, owing to the constraints on work, family and social lives. This finding is also consistent with the previous literature (Brod 2007, 2009).

A number of research studies have examined the impact of infertility treatment on mood at different stages, with most focusing on the impact of failed IVF. Hynes and colleagues (1992) assessed women at presentation for IVF and then following treatment failure. They found that women presenting for infertility treatments were more depressed, had lower self-esteem and were less confident than a control group of fertile women and, after a failed IVF cycle, experienced a further lowering of self-esteem and an increase in depression relative to pre-treatment levels. By contrast, a subsequent systematic review indicated that women starting IVF were only slightly different emotionally from the general population (Verhaak 2007). Unsuccessful treatment raised the women's levels of negative emotions, which continued after consecutive unsuccessful cycles. In general, most women proved to adjust well to unsuccessful IVF, although a considerable number showed subclinical emotional problems. When IVF resulted in pregnancy, the negative emotions disappeared, indicating that treatment-induced stress is considerably related to the threat of failure. Therefore, we could infer from the studies comparing women undergoing repeated IVF cycles with first-time participants that repeated treatment may lead to an increase in depressive symptoms.

\section{Effects of infertility medication}

The psychological impact of infertility medication (in particular clomifene citrate) may be an important independent risk factor for the development of depression, as it dramatically alters serum levels of oestrogen and progesterone (Choi 2005). However, only a few studies and case reports have investigated this matter. Clomifene has been associated with increased irritability, emotionality and exacerbated symptoms of premenstrual syndrome (Blenner 1991), and with increased fatigue at mid-cycle, a time when estradiol levels are highest (Williams 2007).

\section{Influence of psychological state on treatment outcome}

The outcome of infertility treatment may also be influenced by psychological factors. A number of 
studies have examined stress and mood states as predictors of outcome in assisted reproduction. The majority of these support the theory that emotional distress (as defined above, tension, nervousness or worry not fulfilling criteria for a diagnosis of depression or anxiety disorder) is associated with lower pregnancy rates among women pursuing infertility treatment (Sanders 1999; Smeenk 2001).

Very few studies have considered women who meet full criteria for a mood disorder. One reported that women with major depression had lower rates of pregnancy following IVF than non-depressed women (Thiering 1993). Two further studies, which controlled for several confounders (age, number of previous pregnancies and number of embryos transferred), both noted that depression had an independent and significant correlation with lower pregnancy rates (Demyttenaere 1998; Smeenk 2001). State anxiety and a depressive coping style were strongly associated with lower pregnancy rates compared with controls. These findings contrast with those of other studies that found minimal psychological disturbance induced by the infertility treatment process or IVF failure, but in general these studies did not control for confounding variables such as age, duration of treatment or embryo status (Boivin 1996, 2011a; Paulson 1988). A meta-analysis concluded that emotional distress caused by infertility does not compromise the chance of becoming pregnant (Boivin 2011b), highlighting again the fact that there is a complex relationship between stress and IVF outcome.

\section{Drop-out from infertility treatment}

There has been an increasing interest in studying the factors that contribute to drop-out from infertility treatment, since those who do not complete treatment are often not included or decline to participate in studies. Research suggests that a significant proportion of those who drop out of treatment do so because of psychological factors such as emotional distress. A number of studies have reported that among women receiving treatment for infertility, psychological stress is consistently reported as the most frequent reason for early discontinuation (Olivius 2004; Brandes 2009; Van den Broeck 2009). Other reasons are financial burden, a negative effect on social contacts and the perception that staff lack expertise (Van den Broeck 2009).

\section{Psychological management}

Fertility experts are becoming increasingly aware of the importance of providing educational
BOX 2 Approach to infertility counselling

1 Information gathering and analysis: patient-centred care

2 Implications and decision-making counselling: patientcentred care and infertility counselling

3 Supportive counselling: infertility counselling

4 Crisis counselling: psychotherapy

5 Therapeutic counselling: psychotherapy

(Peterson 2012)

interventions to address patients' fears and concerns and to better prepare patients for the demands of treatment. Improving the quality of information provided to patients is one of the easiest ways to improve patient experiences (Bunge 2010; Dancet 2010). Box 2 shows a stepwise approach to delivering infertility-oriented psychological help that can be used by mental health professionals and other physicians.

Current recommendations suggest that staff should try to adopt a patient-centred approach to infertility counselling, providing sufficient information about the pros and cons of medical treatments to enable patients to make an informed decision (Peterson 2012). The Institute of Medicine in the USA has defined patient-centred healthcare delivery as that which "provides care that is respectful of and responsive to individual patient preferences, needs and values and ensures that patient values guide all clinical decisions' (Institute of Medicine 2001). Risk factors for high distress should be also assessed. These include:

- personal factors: pre-existing psychopathology, primary infertility, being a woman, viewing parenting as a central goal in life, an avoidant coping style

- social factors: poor marital relationship, impoverished social network, frequent reminders of infertility

- treatment-linked factors: side-effects of medication, miscarriage, prior treatment failure.

Several measures have been developed to help staff identify patients who should be referred for psychological support, including SCREENIVF (Verhaak 2010), FertiQoL (Boivin 2011a) and FertiSTAT (Bunting 2010) (Box 3).

\section{Evidence for psychological treatments}

Nearly all studies report that women experience greater amounts of infertility-related stress than men (Greil 2010). Men do experience stress, but seem to be less emotionally affected. Women in 
BOX 3 Rating scales to assess psychological infertility distress

- SCREENIVF: highly predictive of pre-treatment distress

- FertiQoL: assesses impact of fertility problems and treatment on personal, social and relational life domains

- FertiSTAT: helps women and their partners learn about their fertility and engage in behavioural change that could optimise it

general have a more positive attitude to seeking psychological help and therapy. In a 12-month follow-up study, Domar and colleagues compared pregnancy rates of women undergoing assisted reproduction who were randomly allocated to a group cognitive-behavioural therapy (CBT) designed to decrease depression and anxiety, to a support group, or to routine care. Viable pregnancy rates were $55 \%$ for the CBT group, $54 \%$ for the support group and $20 \%$ for the control group (Domar 2000a). The group CBT and the support group participants experienced significant psychological improvement at 6 and 12 months compared with the control participants, with the CBT participants showing the greatest positive change (Domar 2000b).

A study in which the intervention group received couples counselling focused on education and addressing stress throughout the IVF cycle and the control group received only routine medical care showed that the intervention group had lower anxiety and depression scores, in addition to significantly higher pregnancy rates (Terzioglu 2001).

Pilot studies have also shown decreased levels of hopelessness and low mood and increased psychosocial well-being in women using group spiritual interventions and group art therapy classes (Chan 2012; Hughes 2011).

Conversely, a meta-analysis of psychological interventions found no significant effects on mental health outcomes but a positive effect on pregnancy rates (Hammerli 2009).

Most clinicians offering infertility treatment try to create a culture of patient-centred care to achieve optimal success. Sometimes, the psychological needs of patients can only be met by more in-depth psychosocial interventions that are best delivered by mental health professionals or infertility counsellors. In addition, although data are sparse regarding the pharmacological treatment of patients experiencing infertility, pharmacotherapy remains an important option for women and men who develop depression in the context of infertility and its treatment. A randomised controlled trial comparing the effects of CBT and fluoxetine on depression in infertile women showed that CBT was superior or at least as effective as pharmacotherapy in promoting wellbeing (improvement on measures of social, sexual and marital concerns; acceptance of a child-free lifestyle and rejection of the need for parenthood; and overall reduced stress about infertility) (Faramarzi 2008).

\section{Conclusions}

The relationship between mood disorders and fertility is very complex and a biopsychosocial approach towards diagnosis and management is necessary. Mood disorders may be associated with reduced fertility rates, but the causality is still unclear and probably variable, depending on independent factors, such as the infertility subtype affecting the woman, that need further investigation (Williams 2007).

Further research is necessary to fully understand infertility, its impact on mood and how best manage it. Future studies should try to clarify whether treatment for infertility in itself affects mood, and also if that effect is more pronounced in women with a history of previous mental illness than in those without.

\section{References}

Anderson KM, Sharpe M, Rattray A, et al (2003) Distress and concerns in couples referred to a specialist infertility clinic. Journal of Psychosomatic Research, 54: 353-5.

Balasch J, Gratacós E (2012) Delayed childbearing: effects on fertility and the outcome of pregnancy. Current Opinion in Obstetrics and Gynecology, 24: $187-93$

Baron M, Risch N, Mendlewicz J (1982) Differential fertility in bipolar affective illness. Journal of Affective Disorders, 2: 103-12.

Blenner JL (1991) Clomiphene-induced mood swings. Journal of Obstetric, Gynecologic, \& Neonatal Nursing, 20: 321-7.

Boivin J, Takefman J (1996) Impact of the in-vitro fertilization process on emotional, physical and relational variables. Human Reproduction, 11: 903-7.

Boivin J, Bunting L, Collins JA, et al (2007) International estimates of infertility prevalence and treatment-seeking: potential need and demand for infertility medical care. Human Reproduction, 22: 1506-12.

Boivin J, Takefman J, Braverman A (2011a) Development and preliminary validation of the fertility quality of life (FertiQoL) tool. Human Reproduction, 26: 2084-91.

Boivin J, Griffiths E, Venetis CA (2011b) Emotional distress in infertile women and failure of assisted reproductive technologies: meta-analysis of prospective psychosocial studies. BMJ, 342: d223.

Brandes M, van der Steen JO, Bokdam SB, et al (2009) When and why do subfertile couples discontinue their fertility care? A longitudinal cohort study in a secondary care subfertility population. Human Reproduction, 24: $3127-35$

Brod M, Hoomans EHM, Wiebinga CJ (2007) Understanding the impact of controlled ovarian stimulation (COS) on women's functioning and wellbeing. Human Reproduction, 22: i223-6. 


\section{MCQ answers \\ $1 \mathrm{c} \quad 2 \mathrm{e} \quad 3 \mathrm{e} \quad 4 \mathrm{~b} \quad 5 \mathrm{c}$}

Brod M, Verhaak CM, Wiebinga CJ, et al (2009) Improving clinical understanding of the effect of ovarian stimulation on women's lives. Reproductive BioMedicine Online, 18: 391-400.

Bunge M, Muhlhauser I, Steckelberg A (2010) What constitutes evidencebased patient information? Overview of discussed criteria. Patient Education and Counseling, 78: 316-28.

Bunting L, Boivin J (2010) Development and preliminary validation of the Fertility Status Awareness Toll: FertiSTAT. Human Reproduction, 25: 1722-33.

Calzeroni A, Conte G, Pennati A, et al (1990) Celibacy and fertility rates in patients with major affective disorders: the relevance of delusional symptoms and suicidal behaviour. Acta Psychiatrica Scandinavica, 82: 309-10.

Carter J, Applegarth L, Josephs L, et al (2011) A cross-sectional cohort of infertile women awaiting oocyte donation: the emotional, sexual and quality-of-life impact. Fertility and Sterility, 95: 711-6.

Chan $\mathrm{CH}$, Chan CL, Ng EH, et al (2012) Incorporating spirituality in psychosocial group intervention for women undergoing in vitro fertilization: a prospective randomized controlled study. Psychology and Psychotherapy, 85: 356-73.

Chen TH, Chang SP, Tsai CF, et al (2004) Prevalence of depressive and anxiety disorders in an assisted reproductive technique clinic. Human Reproduction, 19: 2313-8.

Choi SH, Shapiro H, Robinson GE, et al (2005) Psychological side effects of clomiphene citrate and human menopausal gonadropins. Journal of Psychosomatic Obstetrics \& Gynecology, 26: 93-100

Cooper TG, Noonan E, von Eckardstein S (2010) World Health Organization reference values for human semen characteristics. Human Reproduction Update, 16: 231-45.

Coppola D, Russo LJ, Kwarta RF Jr, et al (2007) Evaluating the postmarketing experience of risperidone use during pregnancy: pregnancy and neonatal outcomes. Drug Safety, 30: 247-64.

Cousineau TM, Domar AD (2007) Psychological impact of infertility. Best Practice \& Research: Clinical Obstetrics \& Gynaecology, 2: 293-308.

Dancet EA, Nelen WL, Sermeus W, et al (2010) The patients' perspective on fertility care: a systematic review. Human Reproduction Update, 16: 467-87.

Deka PK, Sarma S (2010) Psychological aspects of infertility. British Journal of Medical Practitioners, 3: a336.

Demyttenaere K, Bonte L, Ghedolf M, et al (1998) Coping style and depression level influence outcome in in vitro fertilization. Fertility and Sterility, 69: 1026-33

Domar AD, Clapp D, Slawsby EA, et al (2000a) Impact of group psychological interventions on pregnancy rates in infertile women. Fertility and Sterility, 73: 805-11.

Domar AD, Clapp D, Slawsby E, et al (2000b) The impact of group psychological interventions on distress in infertile women. Health Psychology, 19: 568-75

Domar A, Gordon K, Garcia-Velasco J, et al (2012) Understanding the perceptions of emotional barriers to infertility treatment: a survey in four European countries. Human Reproduction, 27: 1073-9.

Downey J, Yingling S, McKinney M, et al (1989) Mood disorders, psychiatric symptoms, and distress in women presenting for infertility evaluation. Fertility and Sterility, 52: 425-32.

Dunkel-Schetter C, Lobel M (1991) Psychological reaction to infertility. In Infertility. Perspectives from Stress and Coping Research (eds A Stanton, C Dunkel-Schetter): 29-57. Plenum Press.

Faramarzi M, Kheirkhan F, Esmaelzadeh S, et al (2008) Is psychotherapy a reliable alternative to pharmacotherapy to promote the mental health of infertile women? A randomized clinical trial. European Journal of Obstetrics \& Gynecology and Reproductive Biology, 141: 49-53.

Fassino S, Piero A, Boggio S, et al (2002) Anxiety, depression and anger suppression in infertile couples: a controlled study. Human Reproduction, 17: 2986-94.
Gentile S (2008) Pregnancy exposure to serotonin reuptake inhibitors and the risk of spontaneous abortions. CNS Spectrums, 13: 960-6.

Greil Al, Slauson-Blevins K, McQuillan J (2010) The experience of infertility: a review of the recent literature. Sociology of Health \& IIIness, 32: $140-62$.

Habermann F, Fritzsche J, Fuhlbrück F, et al (2013) Atypical antipsychotic drugs and pregnancy outcome: a prospective, cohort study. Journal of Clinical Psychopharmacology, 33: 453-62.

Haddad PM, Wieck A (2004) Antipsychotic-induced hyperprolactinaemia: mechanisms, clinical features and management. Drugs, 64: 2291-314.

Haimovici F, Takahashi K, Anderson DJ (1992) Antifertility effects of antisperm cell-mediated immunity in mice. Journal of Reproductive Immunology, 22: 281-98.

Hammerli K, Znoj H, Barth J (2009) The efficacy of psychological interventions for infertile patients: a meta-analysis examining mental health and pregnancy rates. Human Reproduction Update, 15: 279-95.

Harlow BL, Wise LA, Otto MW, et al (2003) Depression and its influence on reproductive endocrine and menstrual cycle markers associated with perimenopause: the Harvard Study of Moods and Cycles. Archives of General Psychiatry, 60: 29-36.

Hemels ME, Einarson A, Koren G, et al (2005) Antidepressant use during pregnancy and the rates of spontaneous abortions: a meta-analysis. Annals of Pharmacotherapy, 39: 803-9.

Henning K, Straub B (2002) Psychological and psychosomatic aspects of involuntary childlessness: state of research at the end of the 1990s. In Involuntary Childlessness. Psychological Assessment, Counselling and Psychotherapy (ed B Straub): 1-19. Hogrefe and Huber.

Hsu YL, Kuo B J (2002) Evaluations of emotional reactions and coping behaviors as well as correlated factors for infertile couples receiving assisted reproductive technologies. Journal of Nursing Research, 10: 291-301.

Hughes EG, da Silva AM (2011) A pilot study assessing art therapy as a mental health intervention for subfertile women. Human Reproduction, 26: $611-5$

Hynes GJ, Callan VJ, Terry DJ, et al (1992) The psychological well-being of infertile women after a failed IVF attempt: the effects of coping. British Journal of Medical Psychology, 65: 269-78.

Institute of Medicine (2001) Crossing the Quality Chasm: A New Health System for the 21st Century. National Academy Press.

Jonsson SA (1991) Marriage rate and fertility in cycloid psychosis: comparison with affective disorder, schizophrenia and the general population. European Archives of Psychiatry and Clinical Neuroscience, 241: 119-25

Kjaersgaard MIS, Parner ET, Vestergaard M, et al (2013) Prenata antidepressant exposure and risk of spontaneous abortion - a populationbased study. PLOS ONE, 8 (8): e72095.

Kee BS, Jung BJ, Lee SH (2000) A study on psychological strain in IVF patients. Journal of Assisted Reproduction and Genetics, 17: 445-8.

Klock SC (2004) A pilot study of the relationship between serotonin reuptake inhibitors and in vitro fertilization outcome. Fertility and Sterility, 82: 968-9.

Lalos A (1999) Breaking bad news concerning infertility. Human Reproduction, 14: 581-5.

Lapane KL, Zierler S, Lasater TM, et al (1995) Is a history of depressive symptoms associated with an increased risk of infertility in women? Psychosomatic Medicine, 57: 509-13.

Lash MM, Yaghamee A, Strohsnitter W, et al (2008) Association between secondary infertility and fallopian tube obstruction on hysterosalpingography. Journal of Reproductive Medicine, 5: 677-80.

Lok IH, Cheung LP, Chung WS, et al (2002) Psychiatric morbidity amongst infertile Chinese women undergoing treatment with assisted reproductive technology and the impact of treatment failure. Gynecologic and Obstetric Investigation, 53: 195-9. 
McKenna K, Koren G, Tetelbaum M, et al (2005) Pregnancy outcome of women using atypical antipsychotic drugs: a prospective comparative study. Journal of Clinical Psychiatry, 66: 444-9.

Meller WH, Zander KM, Crosby RD, et al (1997) Luteinizing hormone pulse characteristics in depressed women. American Journal of Psychiatry, 154: 1454-5

Menning BE (1980) The emotional needs of infertile couples. Fertility and Sterility, 34: 313-9.

Morrell MJ, Isojarvi J, Taylor AE, et al (2003) Higher androgens and weight gain with valproate compared with lamotrigine for epilepsy. Epilepsy Research, 5: 189-99

Moura-Ramos M, Gameiro S, Canavarro MC, et al (2012) The indirect effect of contextual factors on the emotional distress of infertile couples. Psychology and Health, 27: 533-49.

Olivius C, Friden B, Borg G, et al (2004) Why do couples discontinue in vitro fertilization treatment? A cohort study. Fertility and Sterility, 81: 258-61.

Paulson JD, Haarmann BS, Salermo RL, et al (1988) An investigation of the relationship between emotional maladjustment and infertility. Fertility and Sterility, 49: 258-62.

Peterson B, Boivin J, Norre J, et al (2012) An introduction to infertility counseling: a guide for mental health and medical professionals. Journal of Assisted Reproduction and Genetics, 29: 243-8.

Pinborg A, Hougaard CO, Nyboe AA, et al (2009) Prospective longitudinal cohort study on cumulative 5-year delivery and adoption rates among 1338 couples initiating infertility treatment. Human Reproduction, 24: 991-9.

Rasgon N (2004) The relationship between polysytic ovary syndrome and anti-epileptic drugs: a review of the evidence. Journal of Clinical Psychopharmacology, 24: 322-34.
Sanders KA, Bruce NW (1999) Psychosocial stress and treatment outcome following assisted reproductive technology. Human Reproduction, 14 : 1656-62.

Schmidt L, Sobotka T, Bentzen JG, et al (2012) Demographic and medical consequences of the postponement of parenthood. Human Reproduction Update, 18: 29-43.

Smeenk JM, Verhaak CM, Eugster A, et al (2001) The effect of anxiety and depression on the outcome of in-vitro fertilization. Human Reproduction, 16: $1420-3$.

Terzioglu F (2001) Investigation into effectiveness of counselling on assisted reproductive techniques in Turkey. Journal of Psychosomatic Obstetrics \& Gynecology, 22: 133-41.

Thiering P, Beaurepaire J, Jones M, et al (1993) Mood state as a predictor of treatment outcome after in vitro fertilization/embryo transfer technology (IVF/ET). Journal of Psychosomatic Research, 37: 481-91.

Van den Broeck U, Holvoet L, Enzlin P, et al (2009) Reasons for dropout in infertility treatment. Gynecologic and Obstetric Investigation, 68: 58-64.

Verhaak CM, Smeenk JMJ, Evers AWM, et al (2007) Women's emotional adjustment to IVF: a systematic review of 25 years of research. Human Reproduction Update, 13: 27-36.

Verhaak CM, Lintsen AME, Evers AWM, et al (2010) Who is at risk of emotional problems and how do you know? Screening of women going for IVF treatment. Human Reproduction, 25: 1234-40.

Williams KE, Marsh WK, Rasgon NL (2007) Mood disorders and fertility in women: a critical review of the literature and implications for further research. Human Reproduction Update, 13: 607-16.

World Health Organization (2014) Global prevalence of infertility, infecundity and childlessness. WHO (http://www.who.int/ reproductivehealth/topics/infertility/burden/en).

\section{MCQs}

Select the single best option for each question stem

\section{According to the World Health Organization, the prevalence of infertility worldwide is:}

a $20 \%$

b $50 \%$

c $8-12 \%$

d $5-10 \%$

e $6 \%$.

2 Psychological distress related to infertility
pre-treatment is best assessed by the:
a BDI
b FertiQoL
c FertiSTAT
d CTO
e SCREENIVF

\section{Our review of psychotherapies for} psychological distress associated with infertility found no evidence base for:

a cognitive-behavioural therapy

b psychoeducation

c couples counselling

d supportive psychotherapy

e dialectical behaviour therapy.

\section{The incidence of depression in infertile} couples is estimated to be:

a $2 \%$

b $15-54 \%$

c $0.5 \%$

d $40-50 \%$

e $10 \%$.
5 The rate of clinically significant anxiety in infertile couples is estimated to be:

a $1 \%$

b $5 \%$

c $8-28 \%$

d $40 \%$

e $60 \%$. 